useful agent in the management of other children with severe hypertension who are nonresponsive to the usual medical management.

Two important changes in the renin-angiotensin system were observed after treatment with captopril. Captopril lowered plasma aldosterone by blocking the production of angiotensin II, a known stimulator of adrenal aldosterone production. Captopril also increased plasma renin levels, presumably by interrupting the negative feedback loop which controls renin secretion.

Improved creatinine clearance after captopril, which was seen in our patient, has been reported in adults. ${ }^{5}$ The cause of this change is unknown, but renal vasodilatation, decrease in nephrosclerosis, and resolution of the haemolytic syndrome may each have played a role in the patient reported here.

Captopril has several apparent advantages over minoxidil, another agent useful in severe hypertension. ${ }^{7}$ Minoxidil causes pronounced sodium retention which must be aggressively managed with dietary sodium restriction and diuretics. While receiving captopril and frusemide our patient was able to tolerate a high salt diet for treatment of immobilisation hypercalcaemia without adverse effects on blood pressure. The ability to tolerate salt results, in part, from lowered aldosterone levels. The hirsutism caused by minoxidil has limited its usefulness in children.

This patient has had hepatitis throughout the illness. The aetiology of the hepatitis is unknown. The possibility that our patient had an exacerbation of hepatitis due to captopril cannot be completely excluded. However, according to the Squibb monitor, hepatotoxicity has not been observed in other patients receiving captopril.

Captopril was supplied by Squibb under a humanitarian protocol.

\section{References}

1 Trainin E B, Lala V R, Gomez-Leon G, AvRuskin T W. Negative saralasin response in correctable renovascular hypertension. J Pediatr 1978; 93: 460-2.

2 Ondetti M A, Rubin B, Cushman D W. Design of specific inhibitors of angiotensin-converting enzyme. New class of orally active antihypertensive agents. Science 1977; 196: $441-4$.

3 Brunner $\mathrm{H}$ R, Gavras H, Waeber B, et al. Oral angiotensin-converting enzyme inhibitor in long-term treatment of hypertensive patients. Ann Intern Med 1979; 90: 19-23.

- 4 Ferguson R K, Brunner H R, Turini G A, Gavras H, McKinstry D N. A specific orally active inhibitor of angiotensin-converting enzyme in man. Lancet 1977; i: $775-8$.

5 Hollenberg N K, Swartz S L, Passan D P, Williams G H. Increased glomerular filtration rate after converting enzyme inhibition in essential hypertension. $N$ Engl $J$ Med $1979 ; 301$ : 9-12.

6 Gavras H, Brunner H R, Turini G A, et al. Antihypertensive effect of the oral angiotensin converting-enzyme inhibitor SQ 14225 in man. $N$ Engl $J$ Med 1978; 298: 991-5.

7 Peltinger W A, Mitchell H C. Minoxidil-an alternative to nephrectomy for refractory hypertension. $N$ Engl $J$ Med 1973; 289: 167-71.

Correspondence to Dr W R Griswold, University Hospital, Pediatric Nephrology (H 814 E), 225 W Dickinson Street, San Diego, California 92103, USA.

Received 5 October 1981

\title{
Oxygen embolus during mechanical ventilation with disappearance of signs after death
}

\section{P T RUDD AND J S WIGGLESWORTH}

\section{Department of Paediatrics and Neonatal Medicine, Hammersmith Hospital, London}

SUMMARY Oxygen embolus is thought to be a rare complication of mechanical ventilation in preterm infants. In the patient described there was clinical and radiological evidence of embolisation within the heart and great vessels, but at necropsy gas was seen only in the cerebral arteries.

\section{Case report}

This boy (birthweight $900 \mathrm{~g}$ ) was the second of undiagnosed twins delivered by lower segment caesarean section from a woman with severe preeclampsia at 29 weeks' gestation. He was transferred to this hospital at 4 hours, receiving artificial ventilation because of idiopathic respiratory distress syndrome (LS ratio $1 \cdot 5: 1)$. Despite ventilation at low peak pressure $(14 / 2 \mathrm{~cm}$ of water) he developed pulmonary interstitial emphysema followed by a pneumothorax at 26 hours. A chest drain was inserted but he became acidotic and hypoxic, responding to high rates of ventilation as well as to buffer and 
tolazoline. When 40 hours old, while ventilated in $100 \% \mathrm{O}_{2}$ at a pressure of $26 / 2 \mathrm{~cm}$ of water, he became bradycardic and hypoxic. Transillumination of the chest failed to show a pneumothorax and there was no improvement in his condition after reintubation. During resuscitation blood was withdrawn from the umbilical artery catheter and this was found to be mixed with gas. Just before death crepitus was detected in the neck, and the skin over the blood vessels of the face and neck became white. An $x$-ray film at this time (Fig. 1) showed gas in the portal circulation, in the chambers of the heart, and the vessels of the neck. A chest $x$-ray film taken at the start of the necropsy examination 24 hours later (Fig. 2) showed no evidence of intravascular gas, but examination of the infant showed features of hyaline membrane disease and pulmonary interstitial emphysema, with gas bubbles present only in the anterior cerebral arteries.

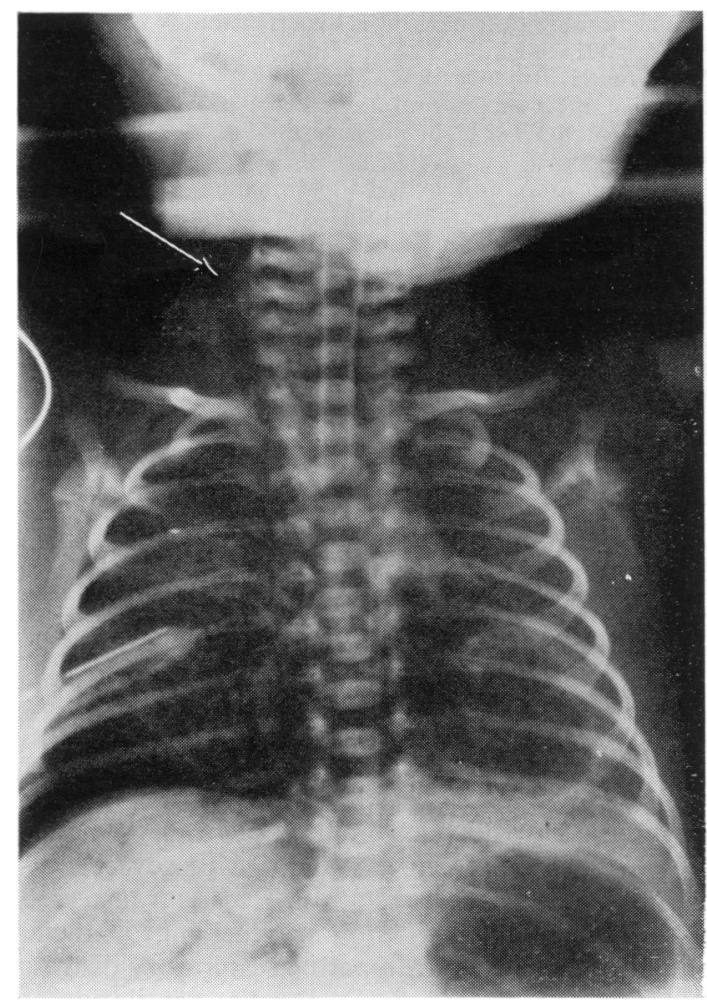

Fig. 1 Chest $x$-ray film at the time of death showing gas outlining the cardiac chambers, with gas in the hepatic arteries as well as in major vessels of the head and neck. Oxygen in the carotid artery is shown by arrow.

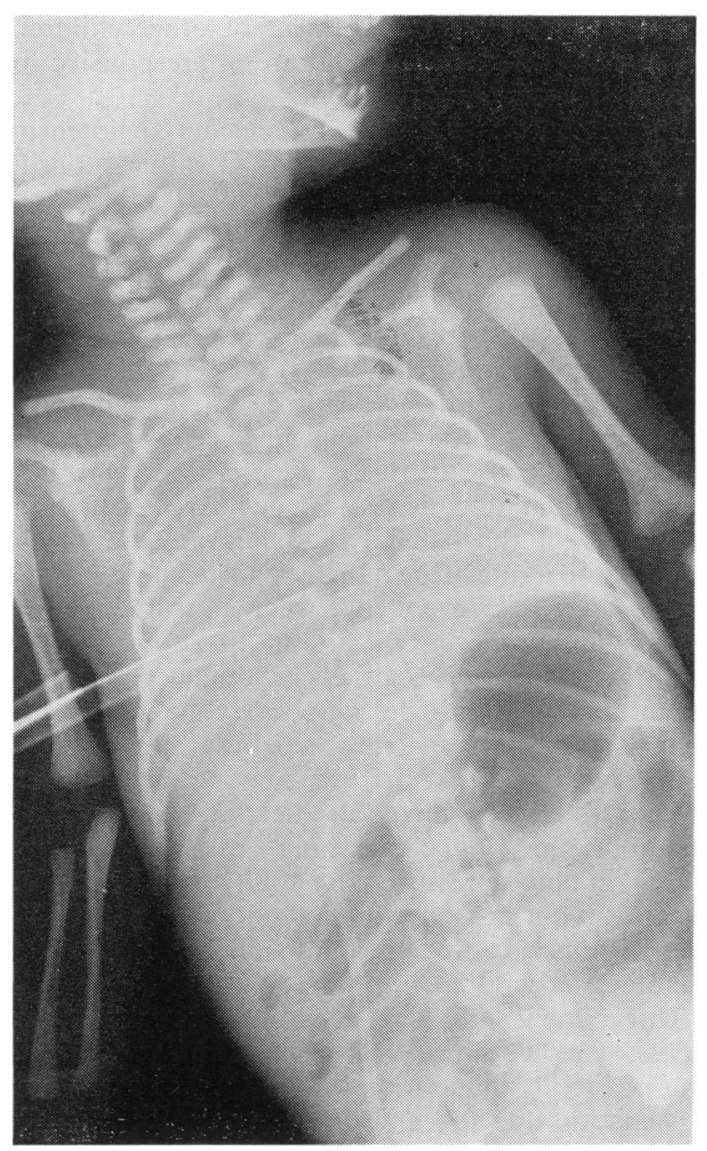

Fig. 2 Chest $x$-ray film taken 24 hours after death.

\section{Discussion}

Gas embolism has been described in infants receiving mechanical ventilation. ${ }^{1-6}$ In previous reports pulmonary interstitial emphysema, ${ }^{145}$ or pneumothorax ${ }^{14}$ was evident before embolisation occurred. Although many of the infants reported were ventilated at high peak inspiratory pressures, in others the pressure was less than $30 \mathrm{~cm}$ of water, ${ }^{15}$ as in our case.

It is suggested that gas enters the pulmonary venous system and is sucked into the systemic circulation when alveoli burst during mechanical ventilation and when the intra-alveolar pressure exceeds the pulmonary venous pressure. ${ }^{26}$ In experiments on cat lungs, Grosfeld et al. ${ }^{7}$ showed that at ventilatory pressures of $50 \mathrm{~cm}$ of water pneumothorax and pneumomediastinum occurred, while at $70 \mathrm{~cm}$ of water there was intracardiac gas embolisation. 
We suspect that oxygen embolisation occurs more frequently than has been reported, as infants may collapse and die too quickly for a chest $x$-ray film to be performed in life. Radiology at necropsy has been recommended as an aid to detection of air embolism, ${ }^{8}$ but this may be misleading in cases of oxygen embolism as this gas will diffuse out of the circulation after death.

\section{References}

1 Kogutt M S. Systemic air embolism secondary to respiratory therapy in the neonate: six cases, including one survivor. AJR $1978 ; 131$ : 425-9.

2 Blanco C E, Rietveld L A C, Ruys J H. Systemic air embolism. A possible complication of artificial ventilation. Acta Paediatr Scand 1979; 68: 925-7.

3 Gregory G A, Tooley W H. Gas embolism in hyaline membrane disease. $N$ Engl J Med 1970; 282: 1141-2.
4 Bowen F W, Jr, Chandra R, Avery G B. Pulmonary interstitial emphysema with gas embolism in hyaline membrane disease. Am J Dis Child 1973; 126: 117-8.

5 Siegle R L, Eyal F G, Rabinowitz J G. Air embolism following pulmonary interstitial emphysema in hyaline membrane disease. Clin Radiol 1976; $27: 77-80$.

6 Brown Z A, Clark J M, Jung A L. Systemic gas embolus. A discussion of its pathogenesis in the neonate with a review of the literature. Am J Dis Child 1977; 131 : 984-5.

? Grosfeld J L, Boger D, Clatworthy H W. Hemodynamic and manometric observations in experimental air block syndrome. J Pediatr Surg 1971; 6: 339-44.

8 Barson A J, Langley F A, Russell J G B. Uses of routine post mortem radiography (abstract). Arch Dis Child 1974; 49: 74.

Correspondence to Dr J Wigglesworth, Department of Paediatrics and Neonatal Medicine, Hammersmith Hospital, Du Cane Road, London W12 0HS.

Received 6 November 1981 